\title{
High public appreciation for the cultural ecosystem services of urban and peri-urban forests during the COVID-19 pandemic
}

\author{
Angela Beckmann-Wübbelt ${ }^{\mathrm{a}, \mathrm{b}}$, Annika Fricke ${ }^{\mathrm{a}}$, Zita Sebesvari ${ }^{\mathrm{b}}$, Iulia Almeida Yakouchenkova ${ }^{\mathrm{a}}$, \\ Katrin Fröhlich ${ }^{a}$, Somidh Saha ${ }^{\text {a,c,* }}$ \\ ${ }^{a}$ Institute for Technology Assessment and Systems Analysis (ITAS), Karlsruhe Institute of Technology, Karlstr.11, D-76133 Karlsruhe, Germany \\ ${ }^{\mathrm{b}}$ Environmental Vulnerability and Ecosystem Services, Institute for Environment and Human Security, United Nations University, Platz der Vereinten Nationen 1, D- \\ 53113 Bonn, Germany \\ ${ }^{\mathrm{c}}$ Chair of Silviculture, Institute of Forest Sciences, University of Freiburg, Tennenbacherstr. 4, D-79085 Freiburg, Germany
}

\section{A R T I C L E I N F O}

\section{Keywords:}

Urban forestry

COVID-19 pandemic

Cultural ecosystem services

Participatory mapping

\begin{abstract}
A B S T R A C T
Cultural ecosystem services (CES) of urban and peri-urban forests (UPF) contribute to the urban population's health and well-being. However, UPF face numerous threats from increasing urbanization and climate change. A comprehensive understanding of the flow of the forests' CES between urban and peri-urban areas was lacking. Further, there is little empirical evidence of how people valued and used UPF during the COVID-19 pandemic. In this study, we assessed residents' perceptions of CES provided by UPF, and their spatial distribution in Karlsruhe and Rheinstetten, Germany, using a participatory map-based questionnaire survey. Respondents $(n=501)$ were asked to indicate five preferred locations of UPF and to rate the individual UPFs' importance concerning various CES. Heatmaps were created to visualize the results, and normalized ratings of the perceptions were examined. The study demonstrated that residents prefer nearby locations for all studied CES but place a higher value on peri-urban forests regardless of their frequency of use. The survey results show an increase in visits to UPFs during the COVID-19 pandemic. The importance of urban forest for citizens' stress reduction during the pandemic was highlighted by the participants. We recommend considering these findings in urban forest planning.
\end{abstract}

\section{Introduction}

Urban and peri-urban forests (UPFs) make an important contribution to the health and well-being of cities' inhabitants and provide a wide range of cultural ecosystem services (CES) (Breuste, 2019; Götzl, 2015). UPFs are defined by the Food and Agriculture Organization (FAO) as "networks or systems comprising all woodlands, groups of trees, and individual trees located in urban and peri-urban areas; they include, therefore, forests, street trees, trees in parks and gardens, and trees in derelict corners" (FAO, 2020). UPFs are declining and losing their potential to provide cultural ecosystem services (CES) (Fischlin et al., 2007) due to urbanization (Referowska-Chodak, 2019), climate change impacts (Dobbs, Eleuterio, Amaya, Montoya, \& Kendal, 2018), and plant diseases (Sieghardt et al., 2005; for definiton of CES see Millennium Ecosystem Assessment, 2003, p. 58).

In a city, where natural open environment is limited and the availability of CES is restricted, UPFs make an important contribution to the physical and mental recreation of the urban population (Jay, Selter, Wurster, \& Schraml, 2016). UPFs are used as a meeting place (Vries et al., 2013) and enhance the appearance of the city (Tyrväinen, Pauleit, Seeland, \& Vries, 2005). UPFs offer a source of inspiration (Riechers, Barkmann, \& Tscharntke, 2016) and have symbolic, cultural, historical (Tyrväinen et al., 2005), spiritual and religious significance for many individuals (Davies et al., 2017), which enhances the emotional bond that people have with places (Salbitano et al., 2016). Further, the urban forest holds important potential for the education of the urban population and their knowledge about nature, tree species and wildlife (Davies et al., 2017; O'Brien, 2009).

UPFs provide preventive health-related services to residents through ecosystem services (Götzl, 2015; Liu \& Russo, 2021; Wu \& Kim, 2021). The World Health Organization (WHO) recognizes this contribution, as shown in its 12 key considerations to prepare cities for the COVID-19 pandemic. One of the considerations is the assurance of access to green spaces in urban areas to promote physical and psychic well-being

\footnotetext{
* Correspondence: Somidh Saha

E-mail address: somidh.saha@kit.edu (S. Saha).
} 
of the cities' inhabitants (WHO, 2020).

The survey for this study was conducted in August and September 2020, a year in which everyday life was at times strongly influenced by the COVID-19 pandemic. To contain the global spread of respiratory tract infections of COVID-19, severe movement restrictions were at times imposed worldwide, restricting or prohibiting gatherings of groups of people. The social life of many people was limited to a minimum. Especially during this period, urban trees and forests moved into the focus of discussions as recreational areas, which contribute to the health and stress-minimization of urban residents. Evaluations of mobile tracking data from Google show a 134\% increase in visits to parks during the pandemic in Baden-Württemberg, the German federal state in which the study area of Karlsruhe and Rheinstetten is located, compared to the reference period before the crisis in January and February 2020 (Google October 4th, 2020). Even though this may partly be due to the better weather conditions in spring, the indicated increase in visits is immense. Although there are still few publications on this topic, as the pandemic is still ongoing, studies by Derks, Giessen, and Winkel (2020), Ugolini et al. (2020), Venter et al. (2020), Xie, Luo, Furuya, and Sun (2020), and Viezzer and Biondi (2021) highlight the importance of UPFs as part of critical infrastructure especially during times of crisis.

Valuation of CES is needed to maintain or enhance the provision of CES from UPFs. However, CES are difficult to characterize, measure, and spatially represent (Gould, Morse, \& Adams, 2019). In the face of a lack of integration of CES in urban forest planning, an increasing number of authors emphasize map-based approaches to assessing CES as particularly important for decision-making (e.g. Baumeister, Gerstenberg, Plieninger, \& Schraml, 2020; Jay et al., 2016). Jay et al. (2016) emphasized that a description of the CES of urban forests, whether qualitative or quantitative, and spatial visualization of them in maps can help to make the quality-of-life factor of urban forests more visible. The spatial visualization of the CES can help foresters and urban planners to design future plans to improve or transform urban green infrastructure (Baumeister et al., 2020). Nitowslawski et al. (2019) found evidence that novel smart forest technologies, including citizens' engagement and participative mapping platforms can maximize green benefits for all city dwellers.

The benefits of ecosystem services from the peri-urban areas surrounding cities have become increasingly important due to urbanization and densification. Urban inhabitants not only receive ecosystem services from trees and forests within the administrative boundary of the city, but also get benefits from the neighboring suburban areas (Breuste, 2019). Forests in the urban hinterland serve as recreational areas for urban residents. Especially where urban forests cannot meet the population's needs, green spaces outside the city contribute to urban residents' healthy living conditions. Therefore, green space conservation is crucial not only for the well-being of peri-urban populations but also for those in urban areas. Ecosystem services are utilized not only by the residents from peri-urban areas but also by the urban inhabitants. Studies such as the one from Machado Junior et al. (2021) highlight the importance of incorporating the relations of dependence in cities with their surroundings, especially in times of crisis. Luederitz et al. (2015) however, identified a knowledge gap in the scales of scientific investigation regarding the local provision of ecosystem services and the wider spatial distribution of potential beneficiaries. Hence, in this study, comprehensive research on the public perception of cultural ecosystem services was undertaken in a large city (Karlsruhe) and a neighboring peri-urban city (Rheinstetten) in southwest Germany. We aimed to quantify CES from the UPF and mapped their spatial distribution pattern through a novel participatory map-based survey during the time of COVID-19 related lockdown.

In order to fulfill the aim of this study, two research questions were formulated:
1 How do residents of Karlsruhe and Rheinstetten evaluate cultural ecosystem services of UPF and how do these perceptions differ between the two municipalities?

Thereby, it will be assessed whether:

a) the residents of both municipalities value the same cultural ecosystem services for urban forests as they do for peri-urban forests, and

b) the citizens value cultural ecosystem services from urban and per$i$-urban areas within their own administrative borders differently than their counterparts from the other municipality.

2 How does the COVID-19 pandemic influence people's perceptions of ecosystem services of trees and forests?

Thereby, it will be assessed whether:

a) the respondents' use of urban forests changed during the pandemic, and b) to what extent the UPF contributed to the respondents' well-being during the pandemic.

\section{Material and methods}

\subsection{Study area}

The study took place in Karlsruhe and Rheinstetten, in the southwestern part of Germany (Fig. 1). With a total population of 304.009 inhabitants, (September 2020), Karlsruhe is the second largest city in the state of Baden-Württemberg (Stadt Karlsruhe, 2020). Population growth averaged $1 \%$ per year over the last decade, which corresponds to twice the national growth rate of Germany (World Bank, 2016). By the end of 2018, the population density of Karlsruhe was 1786 inhabitants per square kilometer. This is more than 2.5 times as many inhabitants per square kilometer as in the municipality of Rheinstetten, which has 675 inhabitants per square kilometer and a total of 20.973 inhabitants (Stadt Karlsruhe, 2020).

We considered forest in Rheinstetten as peri-urban forest, whereas the forest in Karlsruhe was regarded as an urban forest. This classification is justified by the proportions of land use forms of both municipalities. Fig. 1 shows that in Rheinstetten, the built-up area is only about $20 \%$ of the total administrative area, while $73 \%$ of the area is used for agriculture or is woodland and other vegetation. However, in Karlsruhe almost half of the city is covered by residential and transport areas (Statistisches Landesamt Baden-Württemberg, 2020). The size, population density and land use proportions of the two municipalities are comparable with numerous middle-sized cities and their surrounding peri-urban areas in Germany, and across Europe, which are located in similar climate zones. Results may therefore be considered as useful beyond the study area.

The constantly high population growth in Karlsruhe leads to great pressure on the urban forests, as described above. Thus, the city faces the challenge of maintaining an adequate proportion of green space (Nachbarschaftsverb and Karlsruhe, 2019). Creating knowledge concerning the urban forests' value to the city's population is therefore important to support the creation of holistic and shared conservation and management of trees and forests by the city and surrounding communities.

The first COVID-19 case in Karlsruhe was confirmed on February 27th, 2020 (Hofheinz, 2020). Due to the rapid spread of the virus, social distancing policies were imposed in Baden-Württemberg in March, April and May 2020. On 17th March 2020, operations in cultural and educational institutions of all kinds were suspended, as specified in the COVID-19 regulations. On 21st March 2020, restaurants were closed. In addition, from March onwards, no more than three people were allowed to meet in either private or public spaces (Landesregierung Baden-Württemberg, 20AD). From 1st July the number of people allowed to 


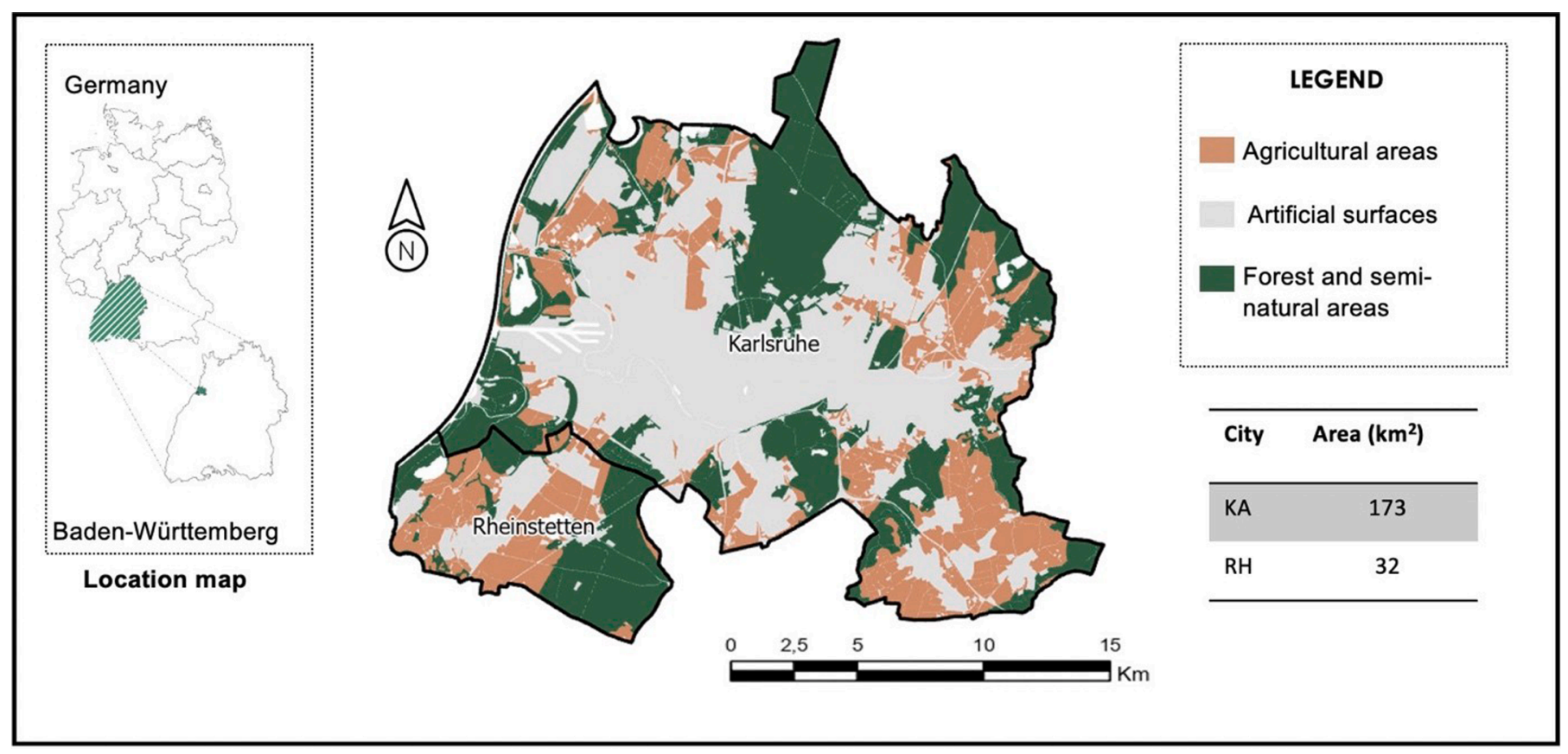

Fig. 1.. Location and land-use of the study area Karlsruhe and Rheinstetten (Remark: this figure should be in color on the printed version).

gather in public and private spaces was increased to 20. Further, restaurants and other leisure facilities opened again, following hygienic restrictions (Landesregierung Baden-Württemberg, 23AD). After the first wave of severe restrictions, in August and September 2020, the time during which the survey for this study was conducted, comparatively few restrictions affected public life.

\subsection{CES included in the study}

Table 1 shows the CES from urban trees and forests considered in this study as defined by the Millennium Ecosystem Assessment (MEA). Short descriptions were added to the questionnaire so that respondents could make a direct association and connection with them (Millennium Ecosystem Assessment, 2003).

Following other studies such as Plieninger, Dijks, Oteros-Rozas, and Bieling (2013), the two additional CES cultural diversity and knowledge systems, as defined by the Millennium Ecosystem Assessment (MEA), were not considered in this study as they are not applicable for assessments on the local level, and cannot be translated to meaningful services of urban forests. Tourism as a cultural ecosystem service was also not included in the study since the focus was on the perceptions of the residents of the two municipalities of Karlsruhe and Rheinstetten.

Multiple demographic information from each respondent and biophysical characteristics of the selected locations were gathered during the survey to examine their influence on perceptions of CES. These are

Table 1.

Definitions of CES in the questionnaire.

\begin{tabular}{ll}
\hline CES & Description \\
\hline Recreation & Use of UPF for leisure activities and exercising \\
Social relations & UPF as meeting places with friends \\
Inspiration & UPF as places for relaxation and sources of inspiration for \\
& new thoughts, ideas, and creative expression \\
Esthetic values & Special beauty \\
Sense of place & A feeling of home and/or connections \\
$\begin{array}{l}\text { Cultural heritage } \\
\text { values }\end{array}$ & Historically important UPF \\
Educational values & UPF as a place of learning about plants and animals \\
Spiritual and religious & Spiritual or religious connection to UPF \\
values &
\end{tabular}

presented in Table 2.

\subsection{Questionnaire}

The questionnaire for this study was created using the survey-tool Maptionnaire (https://maptionnaire.com), which allows the integration of different survey question types with mapping exercises and the collection of spatially referenced answers. The original questionnaire is included in the supplementary material S1.

Before conducting the survey in Karlsruhe and Rheinstetten, four experts with backgrounds in social science, environmental psychology, ecology, and forestry reviewed the questionnaire. The pre-test was carried out both on computers and smartphones to identify any difficulties in the display of the questions and the map. In total, 17 people engaged in two rounds of pretesting. This included students from different disciplines as well as retirees and employees of different ages, levels of education and working sectors. The structure of the questionnaire, the framing of questions, and technical aspects of the spatial

Table 2.

Demographic variables of the respondents and biophysical characters of selected locations that are expected to influence respondents' perceptions of cultural ecosystem services.

\begin{tabular}{|c|c|c|}
\hline \multicolumn{2}{|c|}{ Explanatory variables in regression analyses } & \multirow{2}{*}{$\begin{array}{l}\text { Indicated by respondents } \\
\text { Biophysical variables of the } \\
\text { selected location of UPF }\end{array}$} \\
\hline $\begin{array}{l}\text { Demographic/personal } \\
\text { variables }\end{array}$ & Physical variables & \\
\hline Age & Land use & Diversity of tree species \\
\hline Gender & 1 Artificial area & Quietness \\
\hline Employment status & 2 Agricultural area & Size and vastness \\
\hline Income & 3 Forest and semi- & Stunning design \\
\hline $\begin{array}{l}\text { Population density at } \\
\text { place of residence }\end{array}$ & natural area & Naturalness \\
\hline Nationality & & Proximity to water \\
\hline \multirow{5}{*}{$\begin{array}{l}\text { Access to private or } \\
\text { shared garden }\end{array}$} & & Well-developed road network \\
\hline & & $\begin{array}{l}\text { Wide range of information } \\
\text { available }\end{array}$ \\
\hline & & Wide range of events \\
\hline & & $\begin{array}{l}\text { Proximity to the place of } \\
\text { residence }\end{array}$ \\
\hline & & Attractive location \\
\hline
\end{tabular}


mapping exercise were improved in accordance with the expert review and suggestions from pre-test.

In the introduction, short information on the purpose of the survey was provided. The questionnaire was available in German and English. The questionnaire was divided into six parts.

The first part explored the respondents' familiarity with trees and forests in Karlsruhe and Rheinstetten in general. This included the frequency and duration of participants' visits to UPFs in the two municipalities as well as neighboring municipalities. The respondents' satisfaction with their city's management of trees and forests, as well as whether or not the respondents had access to a private or shared garden, were explored.

The second part was a more general assessment of respondents' valuation of CES from urban trees and forests. Each of the CES presented in Table 1 was measured on a 7-point Likert scale from 1, not important at all, to 7, very important to the respondent (Likert, 1932; Riechers, Strack, Barkmann, \& Tscharntke, 2019). The odd-numbered scale allowed a middle value whenever a respondent did not have a clear opinion on the CES. The 7-point scale serves as an ordinal scale, however, the demand of abstraction and differentiation by respondents is relatively low (Porst, 2014). This allowed us to reach people from all age groups as well as different educational and professional backgrounds.

The third part of the questionnaire assessed respondents' appreciation of trees and forests in Karlsruhe and Rheinstetten, including a participatory mapping exercise. Participants could highlight up to five locations on a map of Karlsruhe and Rheinstetten, indicating where they perceive and appreciate UPFs. A Google-Map was provided since it was confirmed during the pre-testing of the survey that most participants are familiar with it. To identify different locations, participants could zoom in and out, or move on the map as they liked. Furthermore, an option to search for addresses was provided. The administrative boundaries of Karlsruhe and Rheinstetten were demarcated on the map, which allowed the respondents to identify the two cities. After selecting a point on the map, four pop-up questions appeared on the respondent's screen. First, respondents were able to value the eight CES on a 7-point Likert scale for each of the locations. Then, the participants were able to choose from a list of predefined answers, based on the literature, of how they use the selected location. In the next question, the reason for visiting the selected location was asked. Predefined answers for the causes of appreciation were mainly based on the findings of Boll, Haaren, and Ruschkowski (2014), Breuste (2019), and Larson et al. (2019). All questions were in multiple-choice format, and answers were saved spatially referenced. The mapping exercise was either done online or manually on paper maps. The locations mapped on paper by questionnaire respondents were subsequently digitalized using ArcGIS.

In the fourth part, respondents were asked how the COVID-19 pandemic influenced peoples' perceptions and valuations of ecosystem services of trees and forests. Items were presented as statements concerning the use and importance of UPFs for respondents' well-being during the pandemic. Respondents were asked to indicate their agreement on a 7-point Likert scale ( $1=$ do not agree at all; $7=$ fully agree).

In part five of the questionnaire, demographic data were collected for each respondent. These included age, gender, level of education, employment status, nationality, and the postal code of the respondent's residence.

Finishing the survey with part six, the respondents had the opportunity to comment on both the questionnaire itself and the trees and forests in Karlsruhe and Rheinstetten. A free text field was provided for answers. A contact e-mail address was also provided for possible queries.

\subsection{Survey}

The survey was primarily conducted online to obtain the largest and most representative sample possible. It was distributed via various channels such as e-mail distribution lists, newsletters, and social media. 5000 flyers with a short information text and a QR-code leading to the survey were also distributed to pedestrians and mailboxes in the two municipalities. News with information on the survey were published in the official gazettes of the two municipalities. Since the online survey was expected to be a barrier for the participation of elderly people, an analogous paper version was created which was available in the city halls of both cities. The survey ran from August 12th, 2020, to October 1 st, 2020.

\subsection{Data analysis}

\subsubsection{Data preparation}

The non-spatially referenced responses from the survey were downloaded from the Maptionnaire software and stored in a Microsoft Excel spreadsheet. The spatially referenced data were downloaded and stored in shapefiles. The incomplete responses as well as responses from non-residents of either city were not included in this study. An additional variable "population density at the place of residence" has been calculated and added to the data. This variable was based on the postal code indicated by the respondents, the population data per postal code as of $09 / 2020$ provided by the statistics office of the city of Karlsruhe, and the size of each postal code area. Selected UPFs which were outside the boundaries of the two cities were not used for data analysis. IBM SPSS Statistics 26, ArcMap 10.7.1, ArcGIS Pro and Excel 2013 and 2019 were used for the analysis and visualization.

\subsubsection{Visualization of map-based assessments of the selected UPFs by respondents}

Heat maps were created using Kernel density estimation. This has been highlighted by several authors as the most accurate in the identification of hotspots (Hart \& Zandbergen, 2014). For the calculation, the standard search radius (bandwidth) was used. For datasets with low data density, the calculation thus leads to a larger search radius than for datasets with high data density. Since larger search radius parameters result in a smoother, more generalized density grid, the maps for the CES for which fewer points were indicated on the map, appear accordingly. The maps on which more points were indicated appear more highly differentiated. Using the standard radius however, avoids the phenomenon of a ring and the dots that occur with low-density datasets. More information on the functionality of Kernel density estimation is provided in ESRI (2020).

\subsubsection{Normalizing the perceptions of CES in Karlsruhe and Rheinstetten}

To quantify the values of perceptions for each CES in Karlsruhe and Rheinstetten by the residents of the two municipalities, all values have been normalized independently from the total amount of respondents and indicated as locations per municipality. For the exact procedure please consider the supplementary material S2.

\subsubsection{Statistical analyses}

Frequencies and median values were used for descriptive analyses because responses were ordinally scaled. A Mann-Whitney U test was used to identify whether statistically significant differences could be detected in the perceptions of the different CES, both between different locations as well as between the residents of Karlsruhe and Rheinstetten. This is a nonparametric test that, unlike the independent-samples $t$-test, can be used if the independent variable is measured on an ordinal scale (Laerd Statistics, 2015a). Furthermore, another Mann-Whitney U test was used to identify whether statistically significant differences could be detected in the level of agreement with the statements concerning the COVID-19 pandemic between the residents of Karlsruhe and the residents of Rheinstetten.

Ordinal logistic regression has been used to determine whether demographic and land-use variables had a significant influence on the perceptions of the different CES. Further, ordinal logistic regression was used to identify which demographic variables influenced the degree of agreement with the statements concerning the influence of COVID-19 on 
perceptions. Variance Inflation Factor (VIF) was used to identify multicollinearities, which occur whenever one predictor variable in a multiple regression model can be linearly predicted from the others (Laerd Statistics, 2015a). Variables that showed multicollinearities have been excluded from the model.

\section{Results}

\subsection{Respondents' profiles}

A total of 706 people took part in the survey, of which 501 valid responses have been included in the analyses. A majority (80\%) of respondents were from Karlsruhe and the others from Rheinstetten. In total, 216 participants were male, 277 were female and 6 diverse. The average age of the participants was 43 years. About $95 \%$ of the respondents were German, although 18 nationalities were represented among the participants. The majority of the respondents (66\%) had a university degree. $48 \%$ of the respondents had full-time job and the majority (55\%) were employed in the service sector. Respondents' household incomes were relatively evenly distributed among the income categories (Table 3).

\subsection{Respondents' familiarity with trees and forests in Karlsruhe and Rheinstetten}

About $46 \%$ of respondents visited the urban forest in Karlsruhe one to three times a week. A further $35 \%$ of participants visited the urban forest in Karlsruhe daily. $41 \%$ stayed for an average of 30 to $60 \mathrm{~min}$.

Most respondents (about 53\%) visited the peri-urban forest in Rheinstetten less often than once a year. However, of the 260 respondents who visited it more frequently, most of them (101 people) stayed for an average of one to less than three hours. $72 \%$ of participants

Table 3.

Demographic information of respondents (n denotes number of respondents).

\begin{tabular}{|c|c|c|c|}
\hline Attribute & Characteristic & Absolute & Percentage \\
\hline \multirow{2}{*}{$\begin{array}{l}\text { Place of residence }(n= \\
\text { 501) }\end{array}$} & Karlsruhe & 402 & $80.24 \%$ \\
\hline & Rheinstetten & 99 & $19.76 \%$ \\
\hline \multirow{3}{*}{ Gender $(n=499)$} & Male & 216 & $43.29 \%$ \\
\hline & Female & 277 & $55.51 \%$ \\
\hline & Diverse & 6 & $1.20 \%$ \\
\hline Age $(n=420)$ & Average & 42.59 & \\
\hline \multirow{2}{*}{ Nationality $(n=474)$} & German & 449 & $94.73 \%$ \\
\hline & Other & 25 & $5.27 \%$ \\
\hline \multirow[t]{5}{*}{ Education $(n=500)$} & $\begin{array}{l}\text { Secondary school degree } \\
\text { (without allowance to enter } \\
\text { university) }\end{array}$ & 27 & $5.40 \%$ \\
\hline & $\begin{array}{l}\text { Secondary school degree } \\
\text { (with allowance to enter } \\
\text { university) }\end{array}$ & 82 & $16.40 \%$ \\
\hline & $\begin{array}{l}\text { Completed vocational } \\
\text { training }\end{array}$ & 51 & $10.20 \%$ \\
\hline & University degree & 332 & $66.40 \%$ \\
\hline & Other & 8 & $1.60 \%$ \\
\hline \multirow[t]{6}{*}{$\begin{array}{l}\text { Employment status ( } n \\
\quad=499 \text { ) }\end{array}$} & $\begin{array}{l}\text { Full-time employed (min. } 35 \mathrm{~h} \\
\text { per week) }\end{array}$ & 240 & $48.10 \%$ \\
\hline & $\begin{array}{l}\text { Part-time employed (min. } 15 \\
\text { h per week) }\end{array}$ & 85 & $17.03 \%$ \\
\hline & Trainee, pupil, student & 85 & $17.03 \%$ \\
\hline & Parental leave & 10 & $2.00 \%$ \\
\hline & Retiree, pensioner & 54 & $10.82 \%$ \\
\hline & Other & 25 & $5.01 \%$ \\
\hline \multirow{7}{*}{$\begin{array}{l}\text { Net household income } \\
\text { per month }(n=427)\end{array}$} & less than $750 €$ & 36 & $8.43 \%$ \\
\hline & $750 €$ to less than $1.500 €$ & 48 & $11.24 \%$ \\
\hline & $1.500 €$ to less than $2.250 €$ & 64 & $14.99 \%$ \\
\hline & $2.250 €$ to less than $3.000 €$ & 63 & $14.75 \%$ \\
\hline & $3.000 €$ to less than $4.000 €$ & 83 & $19.44 \%$ \\
\hline & $4.000 €$ to less than $5.000 €$ & 68 & $15.93 \%$ \\
\hline & $5.000 €$ or more & 65 & $15.22 \%$ \\
\hline
\end{tabular}

stated that they also visited the peri-urban forest in neighboring communities. Ettlingen, which is a neighboring community of Rheinstetten, was named most frequently. Approximately half of the respondents (57\%) had a garden or access to a shared garden. Graphical figures concerning the respondents' familiarity with urban forests in Karlsruhe and Rheinstetten can be found in the supplementary materials S3, S4 and S5.

\subsection{The general perception of cultural ecosystem services}

In general, almost all CES from UPF were valued as important. Medians were between five (moderately important) and seven (very important) in both cities. However, the spiritual and religious CES were not highly valued by most respondents (see supplementary material S6). The most highly valued for both groups was recreation, with a median of seven in the valuation. No significant differences between the perceptions of the residents of Karlsruhe and the residents of Rheinstetten were detected.

\subsection{Perceptions of cultural ecosystem services from UPF in Karlsruhe and Rheinstetten}

\subsubsection{Spatial distribution of indicated locations}

In total, 1580 locations were marked on the map as perceived most important for the supply of CES by trees and forests in Karlsruhe and Rheinstetten. Their distribution, weighted by the sum indicated importance for the eight CES, are presented in the maps in Fig. 2.

In the density maps it becomes evident that both groups of inhabitants perceived CES mainly within their own administrative borders. However, some hotspots may also be identified in the other municipality. For example, the castle and its park in Karlsruhe had a wide-reaching importance for inhabitants of both Karlsruhe and Rheinstetten.

Table 4 summarizes the most important places perceived as most important for each of the CES. These have been identified from differentiated heatmaps that can be found in the supplementary material S7. They indicate locations that were often chosen by the different user groups as important to their perception of the individual CES and that consequently appeared as hotspots. It becomes clear that some locations, such as the castle and its surrounding parks in Karlsruhe, or the Ferma Lake in Rheinstetten, were perceived as important for the provision of multiple CES. Other locations, such as cemeteries, were almost exclusively perceived as important for the supply of spiritual and religious services. Further, important locations have been highlighted by both groups of residents, from Rheinstetten as well as Karlsruhe.

\subsubsection{Perception of CES flows}

The perceptions of the two groups of residents were assessed individually and differences in perceptions between the two locations have been identified. Thereby, the flow of CES between the two communities is highlighted (see Fig. 3).

It became evident that for Karlsruhe residents all CES, except spiritual and religious values, were perceived as more important in Rheinstetten than within their own administrative borders. Rheinstetten residents also valued all CES from the peri-urban forest higher than from the urban forest in Karlsruhe, except social relations values and spiritual and religious values. A flow of CES from the peri-urban to the urban area is therefore more dominant than the flow of CES from the urban to the peri-urban area. Results of the Mann-Whitney U test showed a statistically significant difference between Karlsruhe and Rheinstetten for the perception of recreational values. The recreational aspect was valued significantly higher in Rheinstetten than by the inhabitants of Karlsruhe in their own municipality. The flow of recreational values from the peri-urban forest in Rheinstetten towards Karlsruhe's residents has therefore been highlighted in Fig. 3. No statistically significant difference between Karlsruhe and Rheinstetten could be detected for any of 


\section{Comparing the perceptions of cultural ecosystem services by the residents of Karlsruhe and Rheinstetten}
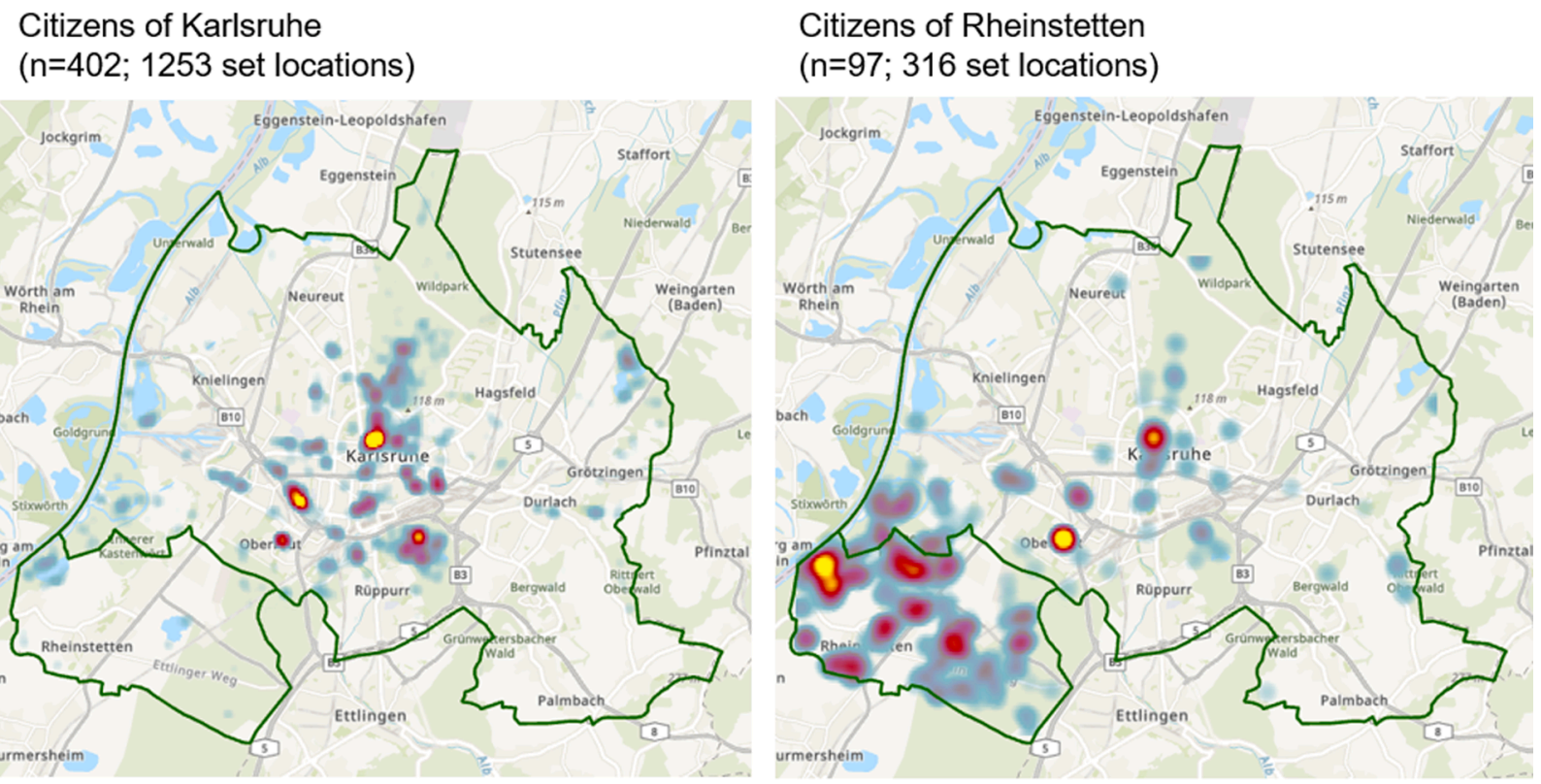

\section{Legend}

\section{Research area Karlsruhe and Rheinstetten}

\section{sparse \\ Density of indicated locations (weighted by the sum of perception values for all CES) \\ dense}

Fig. 2.. Heatmaps of CES perceptions of Karlsruhe and Rheinstetten residents. The maps were calculated using Kernel density standard search radius. (Remark: this figure should be in color on the printed version).

Table 4.

Most often indicated locations for the perception of the eight CES by the different groups of respondents as assessed from the created heatmaps (including locations with a perception value of at least 6/7 points on the Likert scale).

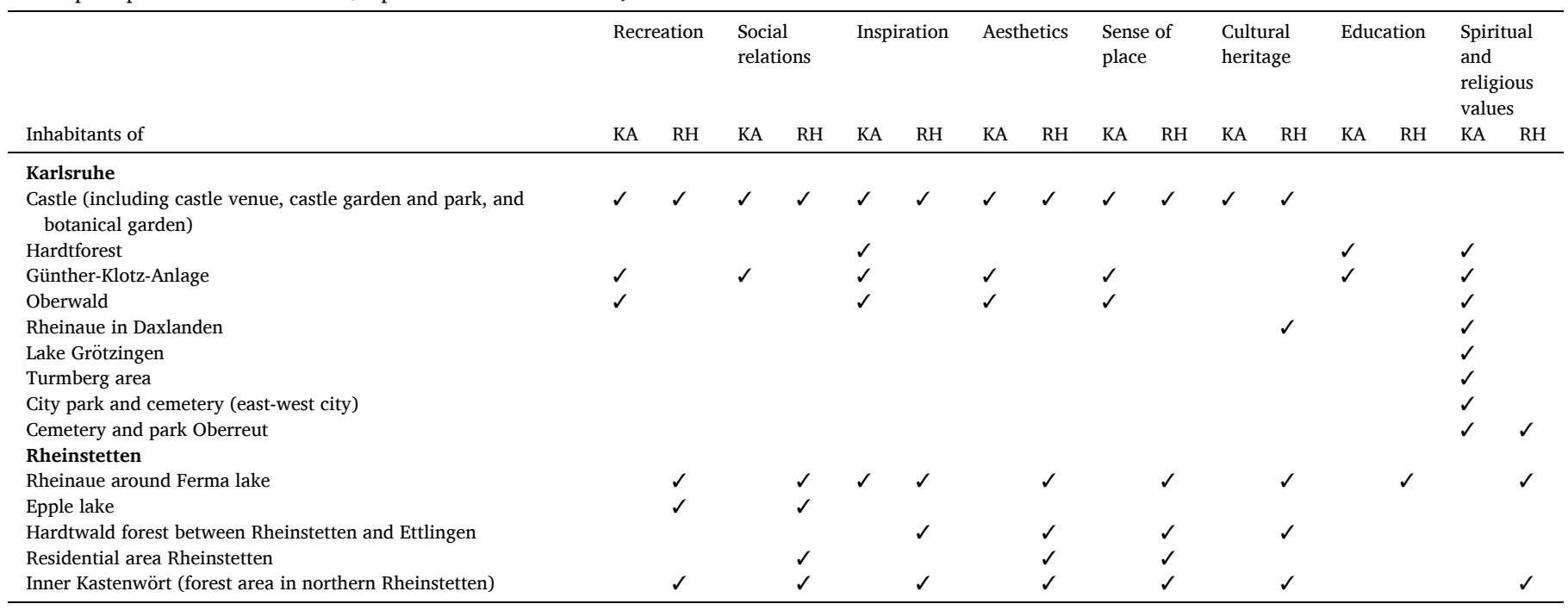

the remaining seven CES perceptions by the inhabitants of Karlsruhe.

\subsubsection{Use of UPFs and reasons for its appreciation}

Within the mapping exercise, respondents were asked to indicate how they use their chosen location on the map. Predefined answers were given based on the literature review. For all locations, walking and relaxing were the most often indicated use, regardless of the participant's place of residence. Hunting was the use stated for the fewest 


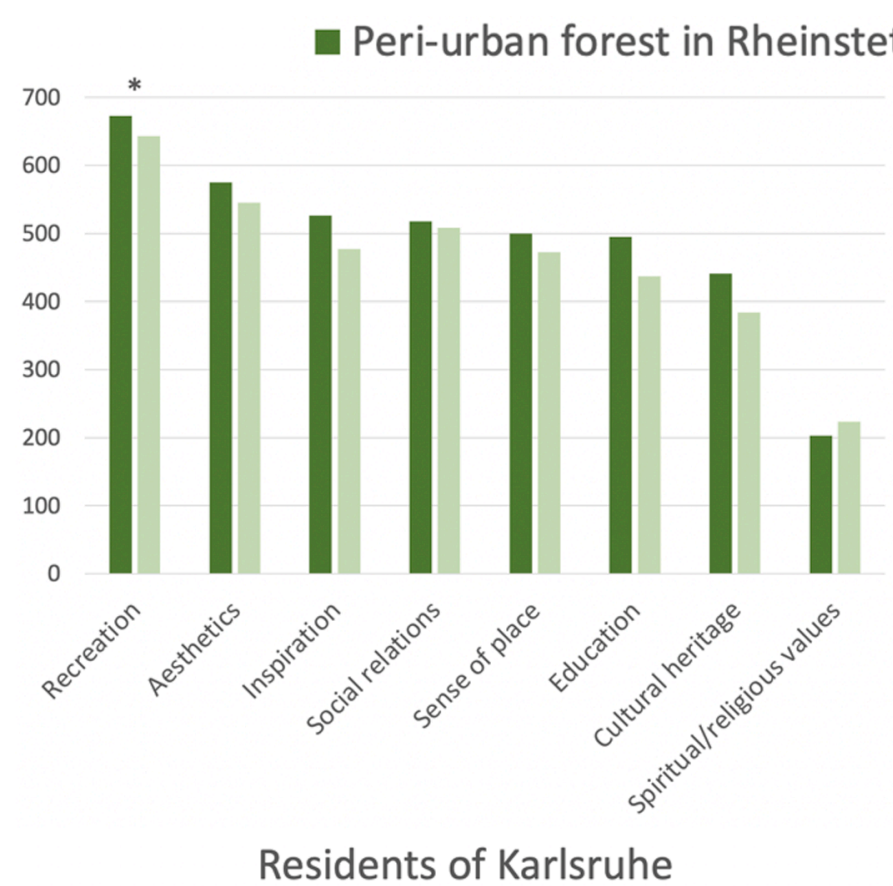

\section{Urban forest in Karlsruhe}

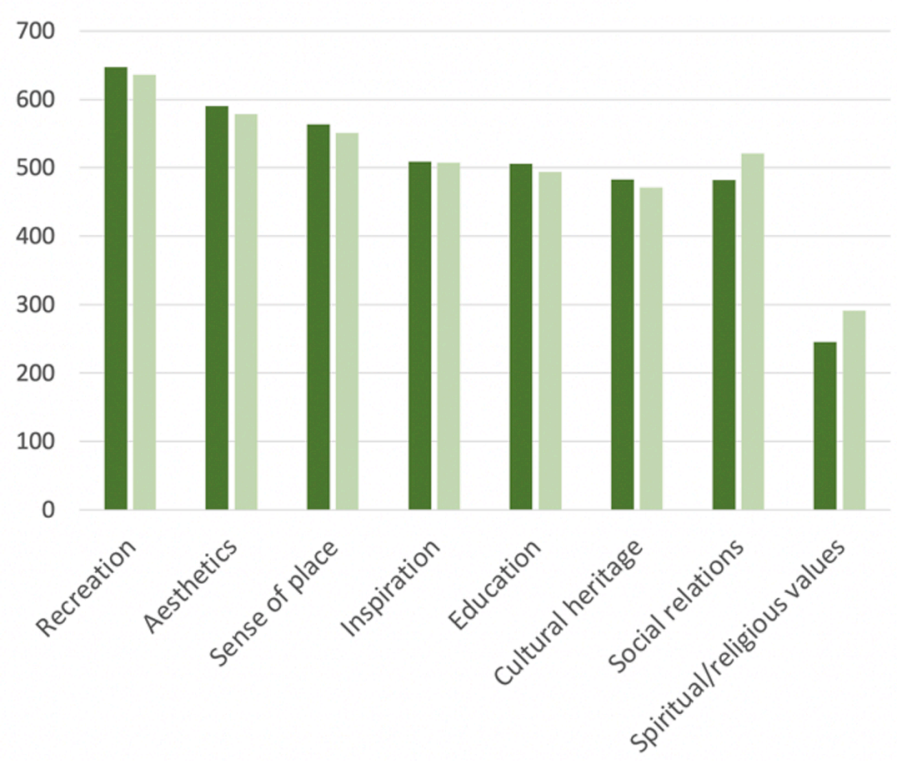

Residents of Rheinstetten

Fig. 3.. CES perceptions in Karlsruhe and Rheinstetten. Value marked with * shows statistically significant difference in the perceptions. (Remark: this figure should be in color on the printed version).

locations.

Karlsruhe residents used the urban forest within their municipality to meet friends ( $46 \%$ of locations) and to exercise ( $44 \%$ of locations). In Rheinstetten, exercising ( $48 \%$ of locations) was followed by observing and discovering plants and animals ( $43 \%$ of locations). In Karlsruhe, the respondents indicated an average of 3.4 different ways of using the urban forest in one location; in Rheinstetten the average number of different uses was 2.8. This indicates that the urban forest in Karlsruhe is used more diversely than the peri-urban forest in Rheinstetten.

The size and vastness of the location was the most often indicated reason to perceive CES. For the locations in Karlsruhe itself, the residents indicated proximity to their place of residence as the second most important reason ( $47 \%$ of locations), followed by quietness $(43 \%$ of locations) and a well-developed road network (38\% of locations). The proximity of water ( $63 \%$ of locations) as well as the naturalness $(63 \%$ of locations) and quietness (63\% of locations) of the locations was more often indicated as an important reason for them to use peri-urban forests in Rheinstetten. For more details on the use and reasons for use of the different locations please consider the supplementary materials S8 and S9.

\subsubsection{Demographic variables influencing the CES perceptions}

In all locations, increased age of participants was associated with an increase in the odds of valuing CES as important. Only social relation values were perceived as more important by younger residents. Nationality was a statistically significant influencing variable for the valuation of spiritual and religious values in both municipalities, whereby the odds of a non-German resident perceiving these values as important was higher than of a German resident. Population density further influenced the perceptions of inspirational and aesthetical values in Karlsruhe. The odds of respondents living in the urban core with a high population density perceiving these values as important was 2.3 times that of a person living in an area with a low population density.

Interestingly, the variable access to a private or shared garden had different, statistically significant, influences on the perceptions of CES in the two municipalities. In Karlsruhe, the odds of participants who have access to a private or shared garden perceiving especially recreational and inspirational values as important was higher than for those who do not have such access. In Rheinstetten, access to a private or shared garden had a negative impact on the perception of social relational and aesthetical values. All significant outcomes of the logistic regression analyzing the influence of demographic factors on the perception of CES are presented in Tables S.2 - S.5 in the supplementary material.

\subsubsection{The influence of land use}

The land use classes of water bodies, agricultural areas, forest and semi-natural areas and artificial areas had a significant influence on the perception of CES for recreation, social relations, inspirational and educational values.

The odds of a location in agricultural and forest and semi-natural areas being perceived as important were higher in Karlsruhe than for locations in artificial areas. The odds of educational values being perceived as important in locations of agricultural areas were 4.3 times that of locations in artificial areas. For locations in forest and seminatural areas, odds were still 3.2 that of locations in artificial areas. However, the odds of a location in artificial areas showing high importance for social relations values was 2.7 times that of a location in forest and semi-natural areas and even 3.5 times that of a location in agricultural areas.

Considering the locations which Karlsruhe's residents indicated as important for the perception of CES in Rheinstetten, the influence of land use becomes explicitly clear when looking at inspirational values. Here, the odds of a location in water bodies showing importance for its perception was 52.3 times that of a location in artificial areas. In agricultural areas it was 15.8 times that of a location in artificial areas, and the odds of a location in forests and semi-natural areas showing importance for inspirational values was 12.6 times that of a location in artificial areas. None of the variables included in the regression influenced the perceptions of the other CES. All significant outcomes of the logistic regression analyzing the influence of land-use factors on the perception of CES are presented in Tables S.6 and S.7 in the supplementary material. 


\subsection{The influence of COVID-19}

\subsubsection{Frequency of use of UPF}

$70 \%$ of the respondents indicated high agreement of five, six or seven (fully agree) with the statement that they visited UPF in Karlsruhe more often during the pandemic restrictions than they did before (see Fig. 4).

The outcome of the regression shows that especially those respondents who do not have access to a private or shared garden, and those who live in the densely populated urban core, visited urban forests in Karlsruhe more often during the pandemic. The odds of respondents who do not have access to a private or shared garden agreeing to the hypothesis were 2.2 times that of a respondent who does have access to a private or shared garden. The odds of a resident of the urban core agreeing with the hypothesis were 3 times that of a resident of the peri-urban area with the lowest population density within the study area.

In contrast, most respondents did not agree that they visited UPF in Rheinstetten more often during the pandemic. Roughly $60 \%$ indicated a level of agreement of either one or two with this statement (see Fig. 4). The regression outcome shows that those who did agree with the statement were most likely to be from the least populated areas. The odds of a resident of the peri-urban area with the lowest population density within the study area agreeing with the statement were 3 times that of a resident of the urban core.

The results of the Mann-Whitney U test confirmed significant differences in agreement with the two statements between the residents of Karlsruhe and those of Rheinstetten, highlighting that the participants primarily visited UPF that lay in their vicinity during the pandemic. The detailed outputs of the Mann-Whitney $U$ test can be found in the appendix S11.

\subsubsection{UPF's contribution to residents' well-being during the pandemic}

Over $90 \%$ of respondents indicated the high importance of UPF for their well-being during the pandemic (see Fig. 4).
The logistic regression showed that UPFs have been especially important for the well-being of those respondents who do not have access to a private or shared garden, employees and students. The odds of respondents who do not have access to a private or shared garden agreeing with the statement of high importance of UPF for their wellbeing during the pandemic is 2.2 times that of a respondent who does have access to a private or shared garden. The odds of part-time employees agreeing with the hypothesis were 10 times that of a retiree/ pensioner. The odds of a student were also 6 times that of a retiree/ pensioner.

\section{Discussion}

\subsection{Perceptions of cultural ecosystem services in urban and peri-urban} areas

We have found that residents put high importance on CES availability in the vicinity of the UPF. This finding is supported by a past study from the city of Karlsruhe, which identified the vicinity of green urban space as the most important factor when visiting and appreciating it. Zhou, Koomen, and van Leeuwen (2018) found that the residents of the Dutch city of Maastricht also preferred nearby locations for the provision of CES. The frequency of selected UPF locations was higher in areas closer to the city center, where population density was also high. This result is supported by the works of Plieninger et al. (2013) who identified that social relations, sense of place, and the inspirational value of urban and peri-urban forests were most frequently ascribed to the settlement area of Gutau in Eastern Germany, within a wider research area. Rall, Bieling, Zytynska, and Haase (2017) also reported a decrease in the density of CES perceived from the inner to the outer areas of the city of Berlin.

The most often selected locations during the mapping exercise by respondents during survey showed a high diversity of uses of CES. It emphasized the importance of CES for the sustainable management of

\section{Especially during the COVID-19 restrictions...}

\section{... I have visited urban and peri-urban forests in Karlsruhe more often than before.}

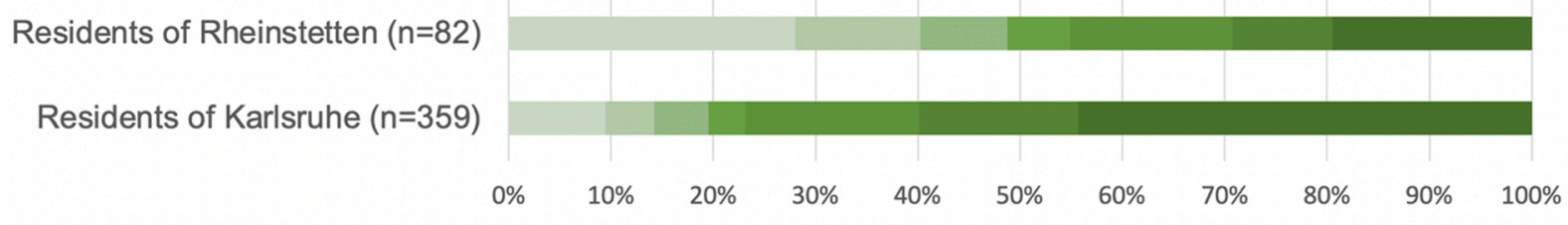

... I have visited urban and peri-urban forests in Rheinstetten more often than before.

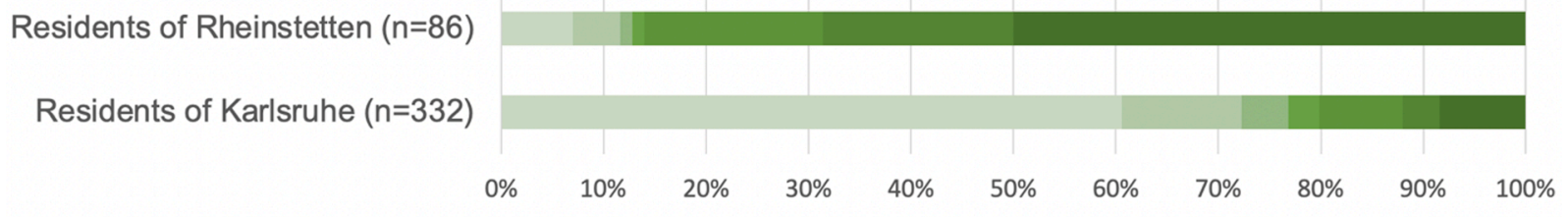

... urban and peri-urban forests are/were important for my well-being.

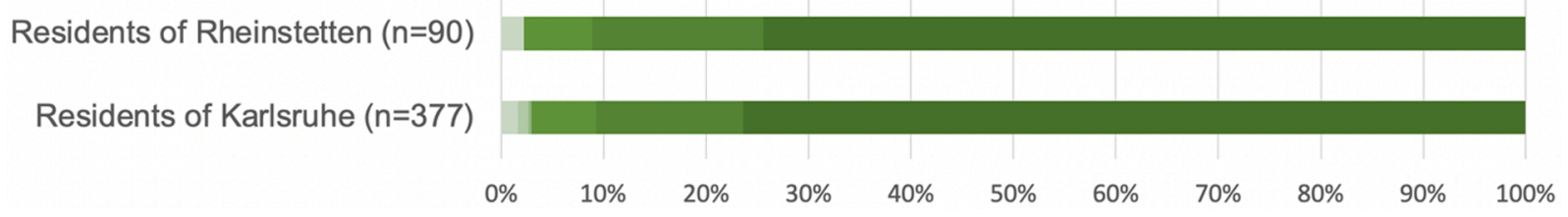

Fig. 4.. Level of agreement on the influence of COVID-19 on the perceptions of UPFs (Remark: this figure should be in color on the printed version). 
the UPFs and corroborated the findings of Chan et al. (2012), who stressed that a full understanding of the use and benefits of CES leads to a socially accepted integration of them into planning and management. We have also shown that the selected UPFs are being used by a variety of people, not only from the vicinity but also from other municipalities. This resulted in an even larger number of requirements towards the locations, and stresses adapted forest management to the population's needs.

Considering perceptions of CES beyond their frequency of use, the results show that Karlsruhe residents stressed the importance of the selected areas outside the city, in Rheinstetten, for all CES studied except spiritual and religious values. This is especially evident for recreational values. Despite the fewer identified locations and lower frequency of use, respondents saw a greater value in the peri-urban forests than in the urban forests. This finding is new to our knowledge; to date, few studies have been conducted that have examined urban populations' perceptions of peri-urban forests. Boll et al. (2014), examined the recreational value of UPF to urban populations. The authors also identified a high preference for recreational value in peri-urban areas, and highlight that this is independent of frequency of use. However, their study did not include other types of CES. Other studies, such as those of or Pan, Marshall, and Maltby (2016)), Radford and James (2013), Riechers et al. (2016), who focused on the perceptions of CES on an urban peri-urban gradient, also identified the high value of peri-urban ecosystems. The authors thereby highlight the adverse effects of urbanization in terms of the provision of ecosystem services and their perception by the population. However, Pan et al. (2016), Radford and James (2013), Riechers et al. (2016), and comparable studies only looked at one end of the gradient. They did not investigate the flow or exchange of ecosystem services between the different localities of investigation.

The results of this study show evidence of the currently prominent scientific mismatch between the scales of investigations regarding the local provision of ecosystem services and the wider spatial distribution of potential beneficiaries identified by Luederitz et al. (2015). The study provides evidence for the hypothesized importance of peri-urban forests for the urban population (e.g. Nowak and Walton (2005)) for all cultural ecosystem services. Therefore, it highlights the importance of scientific research on the role of UPF's in providing ecosystem services beyond administrative borders.

The results of the analysis concerning the influence of land-use variables on CES perceptions in different locations highlight the importance of agricultural and forest, and semi-natural areas compared to a less important artificial surface in Karlsruhe. This finding contradicts findings from other studies. Baumeister et al. (2020) and Plieninger et al. (2013) identified the increased importance of settlement areas for the supply of CES compared to other areas. However, the authors correlated the land use classes with the number of locations indicated on participatory maps. This study's findings show that these can differ strongly from the locations that are perceived as most valuable for the supply of CES by the residents. Considering the density maps, the results concerning the influencing land-use variables of this study would probably have been more in line with the literature, since clear hotspots have been identified mainly in the urban core. The consideration of only four CORINE landcover classes, however, seemed inappropriate for research on local scales. Baumeister et al. (2020) further highlight other physical variables such as proportion of tree cover or proximity to historic sites as important landscape characteristics to influence CES perceptions. Further research will be needed to create a more comprehensive understanding of the importance of different physical attributes of UPF for the perception of CES.

Possible reasons for perceiving CES as important in peri-urban areas as highlighted by Boll et al. (2014) could be higher quality of the visit. The authors state that these result from more diverse and authentic nature. Other authors such as Baumeister et al. (2020) noted the proximity of water as an essential variable when analyzing CES perceptions. This is in line with this study's results, where residents highlighted naturalness and quietness and the proximity of water as reasons for their appreciation of peri-urban areas. Boll et al. (2014) further highlight longer stays or visits in peri-urban areas as a possible reason for high perceptions of CES. This corroborates this study's results, as respondents indicated a longer average duration of stay for visits to peri-urban forests in Rheinstetten than for visits to urban forests in Karlsruhe. The descriptive analysis did not allow more detailed conclusions regarding the explanations for higher perceptions of peri-urban forest's' CES. Qualitative studies that complement this quantitative investigation could help create a deeper understanding of the different perceptions of CES.

\subsection{The influence of COVID-19 on residents' perceptions of urban trees and forests}

High agreement was detected regarding the more frequent use of UPF during the COVID-19 pandemic. This is in line with the findings from Derks et al. (2020), who investigated an increased number of visitors in the peri-urban forest in Kottenforst near Bonn during the pandemic. Further studies such as those of Venter et al. (2020) in Oslo, Norway, show the same trend of an increased number of visitors to the urban forest. An increase in the number of visits to urban green spaces during the pandemic was also detected in the study by Berdejo-Espinola et al. (2021) in Brisbane, Australia. However, the results contradicted the findings of Xie et al. (2020) in Chendung, China, where the number of visits to urban green space decreased. An explanation for the observed patterns is related to the underlying restrictions on movement in the different locations at the time of the conducted surveys. While the survey in Chendung was conducted during a time of severe restrictions, our survey in Karlsruhe took place just after the first wave of severe restrictions when stay-at-home policies were loosened. The suggestion is supported by the findings of Larcher, Pomatto, Battisti, Gullino, and Devecchi (2021) who investigated how respondents in Piedmont, Italy, tended to use urban green spaces much more during the end of the lockdown. The international study of Ugolini et al. (2020), which took place in several European countries, also shows a decrease in visits during the lockdown phases. The same findings of decreased visits during lockdowns and increased numbers of visits to urban green space after lockdown was found by Lopez, Kennedy, and McPhearson (2020) in New York City, and Beria and Lunkar (2021) in Italy.

This study's findings show that respondents preferred to visit UPF within their vicinity, at least in their own municipality. This is in line with Xie et al. (2020), who concluded that this could be related to the government's restrictions on long-distance travel. However, the results contradict the findings from the peri-urban forest close to the city of Bonn, where researchers investigated an increased number of visitors, especially from the neighboring urbanized Rhine Ruhr metropolitan area. Reasons for the results of this study could be that Karlsruhe provides its residents with more urban forest than the Rhine-Ruhr metropolitan region. However, the results must also be viewed critically. Investigations are only partly comparable as international differences in movement restrictions for nature visits differed immensely internationally. Further, in this study, only the neighboring peri-urban forest in Rheinstetten was included. Forests in other neighboring communities were not considered. Since peri-urban forests in other municipalities are visited more frequently by Karlsruhe residents than those in Rheinstetten, other neighboring forests might have had a more important role and recorded a higher influx in visitors from urban Karlsruhe.

The results of the study show strong evidence for the UPFs' important role in urban dwellers' well-being during the time of the COVID-19 pandemic. This supports the often-highlighted contribution of urban forests to the urban population's health and well-being (Jay et al., 2016). It is further in line with Xie et al. (2020), who highlighted the significant improvement of urban residents' health status by visiting urban green areas during the pandemic. Participants in the studies by Berdejo-Espinola et al. (2021) in Brisbane, Australia, and by Lopez et al. 
(2020) in New York City also highlight the important role of spending time in urban nature for their mental health.

Especially employees and students, rather than retirees, stated that UPFs have been important for their well-being during the crisis. The findings are supported by the findings of Berdejo-Espinola et al. (2021), who also found that older people were less likely to increase their green space use during the pandemic. Salari et al. (2020) found that an increase in age is associated with the increased risk of mortality as a consequence of a COVID-19 infection; however, it is the age group 21 to 40 years, that show a significantly increased level of anxiety, depression, and stress, which could be an important reason for them to increase their urban forest use. Further, studies from the United States show that people aged over 65 tend to be more responsive to restriction orders (Engle, Stromme, \& Zhou, 2020). The results of the study by Röhr, Reininghaus, and Riedel-Heller (2020) on mental and social health, which was conducted in Germany during the lockdown in April 2020, support the finding that older individuals are more supportive of government restrictions. However, the results of Fu and Zhai (2021), from analyzing social-distancing behavior during the pandemic in New York City, suggest that public reactions to the pandemic vary and change dynamically over space and time, especially depending on the level of restrictions. That is why the results of this study are only partly comparable.

Besides students and employees, those respondents who do not have access to a private or shared garden stated that urban and peri-urban trees have been essential for their well-being during the crisis. This highlights the importance of aspects of environmental justice in future urban planning. With increasing urbanization and densification in urban areas, a smaller share of the urban population will have access to private and shared gardens, leading to an increased demand for public urban forests and green spaces (Groenewegen, van den Berg, Vries, \& Verheij, 2006).

This study's key observation regarding the impact of COVID-19 on the perceptions of UPF highlighted an increased number of forest visits and the important role of UPFs for the residents' well-being. It thereby revealed the essential role of UPFs as a critical part of the urban population's infrastructure, especially during a crisis. The results can serve as a strong argument when communicating the UPFs' societal functions in policy deliberations, serving as powerful evidence for policymakers and planners to support and advance their conservation. This not only refers to policy discussions that are directly related to the pandemic. Lessons learned from the COVID-19 crisis can also be drawn upon in future discussions. In particular, strategic coalitions between forestry and public health policy areas can be strengthened and intensified based on the results. This will allow forests to be better utilized for human health in the future.

\subsection{Limitations of the study}

While this study's sample was representative of Karlsruhe's and Rheinstetten's populations regarding age, gender, and nationality, it was not representative of education and residential districts. The educational level of the sample was higher than the overall population. Similar phenomena occurred in other studies such as Boll et al. (2014); Krajter Ostoić, Marin, Kičić, and Vuletić (2020). The respondents were also not evenly distributed within the city. We tried to address this problem by normalizing respondents' ratings of preferred locations of the UPF during the spatial mapping exercise.

The questionnaire survey took place in a short period in the summer of 2020. Numerous authors, such as Martín-López, Gómez-Baggethun, Lomas, and Montes (2009), highlight the heterogeneity of CES provided by trees and forests in different seasons. Further studies would be needed to address this.

We could not include more cities due to time and resource limitations. However, as the results show, peri-urban forests in other neighboring communities are also used by residents of Karlsruhe - in some cases more frequently than the forest in Rheinstetten. This warrants a large-scale future study involving multiple cities.

\section{Conclusion}

While proximity to UPF plays an essential role in people's perceptions, the study showed that, in addition, peri-urban forests have an intrinsic value for the urban population, and are perceived by them as more valuable than urban forests in terms of their cultural ecosystem services. A common or joint management plan that incorporates diverse forest requirements, regardless of administrative boundaries, is needed to meet all residents' needs. Further studies on unwanted trade-offs between the assessed perceptions and additional ecosystem services and biodiversity would help to develop these.

During the COVID-19 pandemic, residents of Karlsruhe and Rheinstetten used UPFs significantly more than before. UPFs played an essential role in respondents' well-being during the pandemic. It is expected that these findings can serve as strong evidence for policymakers and planners to support and advance UPFs' conservation. However, further studies are needed to make informed statements about the longterm effects of the COVID-19 pandemic on the perceptions of UPFs.

\section{Funding}

We want to thank the German Aerospace Center (Das Deutsche Zentrum für Luft- und Raumfahrt e.V.) and The Federal Ministry of Education and Research of Germany (Das Bundesministerium für Bildung und Forschung - BMBF) for providing us financial support (GrüneLunge project funding reference number 01LR1726A, https://www.projekt-gruenelunge. de/).

\section{Declaration of Competing Interest}

The authors declare no conflict of interest.

\section{Supplementary materials}

Supplementary material associated with this article can be found, in the online version, at doi:10.1016/j.scs.2021.103240.

\section{References}

Baden-Württemberg, Landesregierung (20.03.2020). Verordnung der Landesregierung über infektionsschützende Maßnahmen gegen die Ausbreitung des Virus SARS-CoV-2 (CoronaVerordnung - Coronavo). Landesregierung Baden-Württemberg. Available online at https://sozialministerium.baden-wuerttemberg.de/fileadmin/redaktion/m-sm/inter $\mathrm{n} /$ downloads/Downloads_Gesundheitsschutz/200320_CoronaVO-konsolidierte_Fass ung_deutsch.pdf. checked on 06/27/2021.

Baden-Württemberg, Landesregierung (23.06.2020). Verordnung der Landesregierung über infektionsschützende Maßnahmen gegen die Ausbreitung des Virus SARS-CoV-2 (CoronaVerordnung - Coronavo). Landesregierung Baden-Württemberg. Available online at https://www.baden-wuerttemberg.de/fileadmin/redaktion/dateien/PDF/Coronain fos/200623 Corona-Verordnung.pdf. checked on 06/27/2021.

Baumeister, CF., Gerstenberg, T., Plieninger, T., \& Schraml, U. (2020). Exploring cultural ecosystem service hotspots: Linking multiple urban forest features with public participation mapping data. Urban Forestry \& Urban Greening, 48, Article 126561. https://doi.org/10.1016/j.ufug.2019.126561

Berdejo-Espinola, V., Suárez-Castro, AF., Amano, T., Fielding, KS., Oh, R. R. Y., \& Fuller, RA. (2021). Urban green space use during a time of stress: A case study during the COVID-19 pandemic in Brisbane, Australia. People and Nature, 3(3), 597-609. https://doi.org/10.1002/pan3.10218

Beria, P., \& Lunkar, V. (2021). Presence and mobility of the population during the first wave of Covid-19 outbreak and lockdown in Italy. Sustainable Cities and Society, 65 (102616). https://doi.org/10.1016/j.scs.2020.102616

Boll, T., Haaren, C.\&., \& Ruschkowski, E. (2014). The preference and actual use of different types of rural recreation areas by urban dwellers-the Hamburg case study. PloS one, 9(10), Article e108638. https://doi.org/10.1371/journal.pone.0108638

Breuste, J. (2019). Die grüne stadt. Stadtnatur als Ideal, Leistungsträger und Konzept für Stadtgestaltung.

Chan, KM. A., Guerry, AD., Balvanera, P., Klain, S., Satterfield, T., Basurto, X., et al. (2012). Where are cultural and social in ecosystem services? A framework for constructive engagement. BioScience,, 62(8), 744-756. https://doi.org/10.1525/ BIO.2012.62.8.7. In BioScience 62 (8), pp. 744-756. 
Davies, H., Doick, K., Handley, P., O'Brien, L., \& Wilson, J. (2017). Delivery of ecosystem services by urban forests. Edinburgh: Forestry Commission (Research report).

Derks, J., Giessen, L.\&., \& Winkel, G. (2020). COVID-19-induced visitor boom reveals the importance of forests as critical infrastructure. Forest Policy and Economics, 118, Article 102253. https://doi.org/10.1016/j.forpol.2020.102253

Dobbs, C., Eleuterio, A., Amaya, J., Montoya, J., \& Kendal, D. (2018). The benefits of urban and peri-urban forestry. Unasylva, 250, 22-29.

Engle, S., Stromme, J., \& Zhou, A. (2020). Staying at home: Mobility effects of Covid-19. CEPR (Covid Economics, 4).

ESRI. (2020). How kernel density works. Available online at https://desktop.arcgis.com/e n/arcmap/latest/tools/spatial-analyst-toolbox/how-kernel-density-works.htm. checked on $12 / 22 / 2020$

FAO. (2020). Urban and peri-urban forestry. Definition. Food and Agriculture Organization of the United Nations (FAO). Available online at http://www.fao.org/forestry/urba nforestry/87025/en/. updated on 10/5/2017, checked on 6/8/2020.

Fischlin, A., Midgley, G. F., Price, J., Leemans, R., Gopal, B., Turley, C., et al. (2007). Ecosystems, their properties, goods, and services. In M. L. Parry, O. F. Canziani, J. P. Palutikof, P. J. van der Linden\&, \& C. E. Hanson (Eds.), Climate change 2007: Impacts, adaptation and vulnerability. contribution of working group II to the fourth assessment report of the intergovernmental panel on climate change (pp. 211-272). Cambridge, UK: Cambridge University Press. Available online at https://www.fs. usda.gov/treesearch/pubs/33102.

Fu, X., \& Zhai, W. (2021). Examining the spatial and temporal relationship between social vulnerability and stay-at-home behaviors in New York City during the COVID19 pandemic. Sustainable Cities and Society, 67(102757). https://doi.org/10.1016/j scs.2021.102757

Google (October 4th, 2020).: Veränderte Mobilitätstrends Deutschland

(Mobilitätsbericht zur Coronakrise). Available online at https://www.google.com/co vid19/mobility/, checked on 10/4/2020.

Götzl, M. (2015). Ökosystemleistungen des Waldes. Erstellung eines Inventars für Österreich (Report /Umweltbundesamt).

Gould, RK., Morse, JW.\&, \& Adams, AB. (2019). Cultural ecosystem services and decision-making: How researchers describe the applications of their work. People and Nature, 1(4), 457-475. https://doi.org/10.1002/pan3.10044

Groenewegen, PP., van den Berg, AE., Vries, S., \& Verheij, RA. (2006). Vitamin G: Effects of green space on health, well-being, and social safety. BMC Public Health, 6, 149. https://doi.org/10.1186/1471-2458-6-149

Hart, T., \& Zandbergen, P. (2014). Kernel density estimation and hotspot mapping. Policing (Bradford, England), 37(2), 305-323. https://doi.org/10.1108/PIJPSM-042013-0039

Hofheinz, M. (2020). Corona-Virus in Karlsruhe: Entwicklungen von Februar bis März 2020. MeinKA. Available online at https://meinka.de/coronavirus-karlsruhe/. checked on $06 / 27 / 2021$

Jay, M., Selter, A., Wurster, M., \& Schraml, U. (2016). Urbaner Wald, urbane Lebensqualität. Die vielfältigen Ökosystemleistungen urbaner Wälder sichtbar machen Ein Handlungsleitfaden. Professur für Forst- und Umweltpolitik, Albert-LudwigsUniversität Freiburg. Arbeitsbericht 01/2016.

Karlsruhe, N. (2019). Umweltbericht. Flächennutzungsplan 2030 (http://www. nachbarschaftsverband-karlsruhe.de/b1/verbandsversammlung/vergangen2019/3. juni 2019/HF sections/content/1584537448420/2 Fl\%C3\%A4chennutzungsplan 2030 Begr\%C3\%BCndung.pdf) last accessed on 12.08.2021.

Krajter Ostoić, S., Marin, A. M., Kičić, M., \& Vuletić, D. (2020). Qualitative exploration of perception and use of cultural ecosystem services from tree-based urban green space in the city of Zagreb (Croatia). Forests, 11(8), 876. https://doi.org/10.3390/ f11080876

Stadt Karlsruhe (2020).: Statistikatlas Karlsruhe: Bevölkerung. Available online at htt ps://web3.karlsruhe.de/Stadtentwicklung/statistik/atlas/, updated on 12/31/2019, checked on $12 / 22 / 2020$

Laerd Statistics (2015a).: Ordinal logistic regression. Available online at https://statist ics.laerd.com/, checked on 11/25/2020.

Larcher, F., Pomatto, E., Battisti, L., Gullino, P., \& Devecchi, M. (2021). Perceptions of urban green areas during the social distancing period for COVID-19 containment in Italy. Horticulturae, 7(55). Available online at https://www.mdpi.com/2311-7524/ 7/3/55.

Larson, KL., Corley, EA., Andrade, R., Hall, SJ., York, AM., Meerow, S., et al. (2019). Subjective evaluations of ecosystem services and disservices: An approach to creating and analyzing robust survey scales. E\&S, 24(2). https://doi.org/10.5751/ ES-10888-240207

Likert, R. (1932). A technique for measurement of attitudes. Archives of Psychology, (140), 5-55.

Liu, OnYi, \& Russo, A. (2021). Assessing the contribution of urban green spaces in green infrastructure strategy planning for urban ecosystem conditions and services. Sustainable Cities and Society, 68(102772). https://doi.org/10.1016/j. scs.2021.102772

B. Lopez; C. Kennedy; T. McPhearson (2020).: Parks are critical urban infrastructure: Perception and use of urban green spaces in NYC during COVID-19. Preprints 2020080620. doi: 10.20944/preprints202008.0620.v2.

Luederitz, C., Brink, E., Gralla, F., Hermelingmeier, V., Meyer, M., Niven, L., et al. (2015). A review of urban ecosystem services: Six key challenges for future research. Ecosystem Services, 14, 98-112. https://doi.org/10.1016/j.ecoser.2015.05.001

Machado, C., Ribeiro, D. M. N. M., \& Viana, A. B. N. (2021). Public health in times of crisis: An overlooked variable in city management theories? Sustainable Cities and Society, 66(102671). https://doi.org/10.1016/j.scs.2020.102671

Martín-López, B., Gómez-Baggethun, E., Lomas, PL., \& Montes, C. (2009). Effects of spatial and temporal scales on cultural services valuation. Journal of Environmental Management, 90(2), 1050-1059. https://doi.org/10.1016/j.jenvman.2008.03.013
Millennium Ecosystem Assessment. (2003). Ecosystems and human well-being. a framework for assessment. Washington, Covelo, London: Island Press.

Nitoslawski, SA., Galle, NJ., Konijnendijk, C., Van Den Bosch, J., \& Steenberg, W. N. (2019). Smarter ecosystems for smarter cities? A review of trends, technologies, and turning points for smart urban forestry. Sustainable Cities and Society, 51(101770). https://doi.org/10.1016/j.scs.2019.101770

Nowak, D., \& Walton, J. T. (2005). Projected urban growth (2000-2050) and its estimated impact on the US forest resource. Journal of Forestry, 383-389.

O'Brien, L. (2009). Learning outdoors: The forest school approach. Education, 37(1) 45-60. https://doi.org/10.1080/03004270802291798. 3-13.

Pan, Y., Marshall, S., \& Maltby, L. (2016). Prioritising ecosystem services in Chinese rural and urban communities. Ecosystem Services, 21, 1-5. https://doi.org/10.1016/j. ecoser.2016.07.011

Plieninger, T., Dijks, S., Oteros-Rozas, E., \& Bieling, C. (2013). Assessing, mapping, and quantifying cultural ecosystem services at community level. Land use policy, 33, 118-129. https://doi.org/10.1016/j.landusepol.2012.12.013

Porst, R. (2014). Fragebogen. Ein Arbeitsbuch. 4., Erweiterte Auflage. Wiesbaden: SPringer VS.

Radford, K. G., \& James, P. (2013). Changes in the value of ecosystem services along a rural-urban gradient: A case study of Greater Manchester, UK. Landscape and Urban Planning, 109(1), 117-127. https://doi.org/10.1016/j.landurbplan.2012.10.007

Rall, E., Bieling, C., Zytynska, S., \& Haase, D. (2017). Exploring city-wide patterns of cultural ecosystem service perceptions and use. Ecological Indicators, 77, 80-95. https://doi.org/10.1016/j.ecolind.2017.02.001

Referowska-Chodak, E. (2019). Pressures and threats to nature related to human activities in European urban and suburban forests. Forests, 10(9), 765. https://doi. org/10.3390/f10090765

Riechers, M., Barkmann, J., \& Tscharntke, T. (2016). Perceptions of cultural ecosystem services from urban green. Ecosystem Services, 17, 33-39. https://doi.org/10.1016/j. ecoser.2015.11.007

Riechers, M., Strack, M., Barkmann, J., \& Tscharntke, T. (2019). Cultural ecosystem services provided by urban green change along an urban-periurban gradient. Sustainability, 11(3), 645. https://doi.org/10.3390/su11030645

S. Röhr; U. Reininghaus; S. Riedel-Heller (2020).: Mental and social health in the German old age population largely unaltered during COVID-19 lockdown: Results of a representative survey.

Salari, N., Hosseinian-Far, A., Jalali, R., Vaisi-Raygani, A., Rasoulpoor, S., Mohammadi, M., et al. (2020). Prevalence of stress, anxiety, depression among the general population during the COVID-19 pandemic: A systematic review and metaanalysis. Globalization and Health, 16(1), 57. https://doi.org/10.1186/s12992-02000589-W

Salbitano, F., Borelli, S., Conigliaro, M., \& Chen, Y. (2016). Guidelines on urban and periurban forestry. Rome: Food and Agriculture Organization of the United Nations (FAO forestry paper, 178).

Sieghardt, M., Mursch-Radlgruber, E., Paoletti, E., Couenberg, E., Dimitrakopoulus, A., Rego, F., et al. (2005). The abiotic urban environment: Impact of urban growing conditions on urban vegetation. In C Konijnendijk, K Nilsson, T Randrup, \& J Schipperijn (Eds.), Urban forests and trees. a reference book (pp. 281-323). Berlin, Heidelberg: Springer-Verlag Berlin Heidelberg.

L. Statistics (2015a): Mann-whitney U test. Available online at https://statistics.laerd. com/, checked on $11 / 25 / 2020$.

Statistisches Landesamt Baden-Württemberg. (2020). Bevölkerung und Gebiet. Fläche seit 1996 nach tatsächlicher Nutzung. Available online at https://www.statistik-bw.de/ BevoelkGebiet/GebietFlaeche/015152xx.tab?R=GS212000. updated on 12/31/ 2019.

Tyrväinen, L., Pauleit, S., Seeland, K., \& Vries, S. (2005). Benefits and uses of urban forests and trees. In C Konijnendijk, K Nilsson, T Randrup, \& J Schipperijn (Eds.), Urban forests and trees. a reference book (pp. 81-114). Berlin, Heidelberg: SpringerVerlag Berlin Heidelberg. Available online at https://www.researchgate.net/publica tion/278702401_Benefits_and_Uses_of_Urban_Forests_and_Trees.

Ugolini, F., Massetti, L., Calaza-Martínez, P., Cariñanos, P., Dobbs, C., Ostoic, S. K., et al. (2020). Effects of the COVID-19 pandemic on the use and perceptions of urban green space: An international exploratory study. Urban Forestry \& Urban Greening, 56, Article 126888. https://doi.org/10.1016/j.ufug.2020.126888

Venter, Z., Barton, D., Gundersen, V., Figari, H., \& Nowell, M. (2020). Urban nature in a time of crisis: Recreational use of green space increases during the COVID-19 outbreak in Oslo, Norway. Environmental Research Letters. https://doi.org/10.1088/ 1748-9326/abb396

Viezzer, J., \& Biondi, D. (2021). The influence of urban, socio-economic, and ecoenvironmental aspects on COVID-19 cases, deaths and mortality: A multi-city case in the Atlantic Forest, Brazil. Sustainable Cities and Society, 69(102859). https://doi. org /10.1016/j.scs.2021.102859

Vries, S., Buijs, AE., Langers, F., Farjon, H., van Hinsberg, A., \& Sijtsma, FJ. (2013). Measuring the attractiveness of Dutch landscapes: Identifying national hotspots of highly valued places using Google Maps. Applied Geography, 45, 220-229. https:// doi.org/10.1016/j.apgeog.2013.09.017

WHO. (2020). Strengthening preparedness for COVID-19 in cities and other urban settings: Interim guidance for local authorities. Geneva: World Health Organization. Edited by.

World Bank. (2016). Population growth (annual \%) of Germany. World Bank. Available online at https://data.worldbank.org/indicator/SP.POP.GROW?locations=DE. checked on $5 / 20 / 2020$. 
Wu, L., \& Kim, S. K. (2021). Health outcomes of urban green space in China: Evidence from Beijing. Sustainable Cities and Society, 65(102604). https://doi.org/10.1016/j. scs.2020.102604

Xie, J., Luo, S., Furuya, K., \& Sun, D. (2020). Urban parks as green buffers during the COVID-19 pandemic. Sustainability, 12(17), 6751. https://doi.org/10.3390/

su12176751
Zhou, T., Koomen, E., \& van Leeuwen, ES. (2018). Residents' preferences for cultural services of the landscape along the urban-rural gradient. Urban Forestry \& Urban Greening, 29, 131-141. https://doi.org/10.1016/j.ufug.2017.11.011 